\title{
Aconselhamento sexual do paraplégico e tetraplégico
}

Fabiano Puhlmann Di Girolamo*

\section{IMPORTÂNCIA}

- $\quad$ A lesão medular afeta a sexualidade.

- O lesado medular é sexuado.

- Tem o direito a informação sobre sexo.

- $\quad$ Pode expressar sua sexualidade de forma livre e responsável.

- Sua vivência sexual facilitará a integração com o meio.

\section{CONCEITUAÇÃO}

- $\quad$ Tipos de lesão - Completa/Incompleta

- Localização:

- Região Cervical (C 1 - C7) - Região Tóraco-lombar (TI - S5)

- Sequielas - Tetraplégia - Seqüelas - Paraplégica

- Tetraparesia - Paraparesia

* Psicoterapêuta especialista em Psicologia de Recuperação pela FMUSP. 


\section{INCIDÊNCIA}

- $\quad 50 \%$ dos casos ocorre entre os 15 a 25 anos (Adultos jovens).

- $\quad 30$ a 35 casos de lesão modular/a cada 1 milhão de habitantes por ano $(2 \%)$.

\section{CAUSAS DO DANO NEUROLÓGICO}

- Traumatismos ( ) - acidentes: de trânsito/trabalho/esportes/armas.

- Outras( )-tumoral/infecciosa/vascular/mal-formações/degenerações.

\section{FUNÇÃO SEXUAL HUMANA}

- Depende da integridade: Gonodal/Endócrina/Neurológica/e Psicológica.

\section{ASPECTOS PSICOLÓGICO (Reações Típicas)}

- Dependência física acompanhada de dependência emocional.

- $\quad$ Atitudes de rejeição da realidade (Persiste até a elaboração das perdas).

- $\quad$ Fase de depressão reativa (Resulta da perda da auto-estima).

- Perda da auto-estima (Confiança e satisfação com o próprio corpo/ Distorção da percepção de adequação à vida com presença de sentimentos de inferioridade e abandono. As pessoas que baseiam sua auto-estima - na capacidade física com maiores dificuldades.

- $\quad$ Conflitos com a imagem corporal (Percepção das partes paralisadas como não próprias./Aparecem sentimentos de vergonha, medo e isolamento com temores da rejeição social e sexual./Necessário desenvolver uma nova vivência corporal-conhecer os limites e modificações./Incorporar os equipamentos Cadeira de Rodas/Muletas/Coletor de urina).

- Identidade sexual (Conflitos com o estereótipo da masculinidade impregnado por idéias de força, agressão e dominação física/Observa-se que os pacientes impotentes consomem muita energia com o próprio corpo restando pouco tempo para atividades sociais cons- 
trutivas/Apresentam também maior repressão e distorções da realidade, bem como depressão).

Obs.: Elaborar a nova imagem corporal e recuperar a auto-estima e a identidade sexual são essenciais para o reequilíbrio da personalidade, surgindo então maior confiança para reassumir um papel sexual e social positivo.

\section{ASPECTO NEUROLÓGICO (Comando Encefálico e Modular)}

Lesão raquimedular (inclusive do cone medular e da cauda eqüina). Pode alterar a função sexual.

\section{MÉDULA VERTEBRAL E A FUNÇÃO SEXUAL HUMANA}

A primeira resposta a estimulação sexual é no homem - (A ereção peniana que resulta da intumescência dos corpos cavernosos e do corpo esponjoso do pênis). Na mulher - (A Intumescência do clítores, dos pequenos e grandes lábios, alongamento dos dois terços posteriores da vagina e produção de muco lubrificante). Estas respostas são desencadeadas por estímulos centrais ou psicogênicos (Medidos pelos órgãos do sentido, por percepção direta ou de memória. E pelos estímulos periféricos (toque das áreas genitais e adjacências). Ocorre também a ereção por estímulos proprioceptivos (como tensão em estruturas internas).

As Aferências Periféricas caminham pelos nervos pudendos, os quais participam do plexo sacral, alcançando a medula ao nível de S2, S3, S4 se dirigindo então para o cérebro. As aferências centrais ativam o centro reflexo medular localizado nos segmentos tóraco-lombares de TI1 a L2.

As Eferências erectivas são influenciadas pelas fibras colinérgicas parassimpáticas dos nervos eretores de Eckhardt, provenientes do centro sacral (S2-S3-S4). O centro reflexo medular para a ereção está também localizados na porção sacra, sendo acionado por estímulos periféricos.

A Emissão -Ejaculação ocorre na fase da emissão por mediação simpática dos nervos hipogástricos, a partir do centro reflexo tóraco-lombar de T11-L2, e na fase de ejaculação estão envolvidos os dois centros medulares reflexos, o que a torna mais complexa. 
O Orgasmo é uma sensação de alto significado psicológico, conscientemente interpretada como satisfação sexual, do ponto de vista físico é uma descarga física, resultante das tensões vasocongestivas miotônicas determinadas pelos estímulos sexuais. (Resulta da percepção das contrações da musculatura lisa dos órgãos genitais internos e da musculatura estriada do períneo, coincide com a emissão-ejaculação).

\section{ANAMNESE DA FUNÇÃO SEXUAL DO LESADO MEDULAR}

Inventário da função sexual anterior a lesão (abrangendo itens como interesse, desempenho, conhecimento sobre sexualidade, hábitos sexuais ...) Incluem-se questões sobre sensibilidade anal, vesical, uretral e genital, forma de controle intestinal e vesical (Reflexa ou voluntário) História de infecções urinárias e do trato genital, presença de fístula uretrais, informações sobre infiltrações nervosas com álcool ou fenol, história de práticas para o controle da espasticidade. No homem perguntar se tem ereção espontânea, reflexa (como ocorreu) ou psicogenica, se tem ejaculação, sensação de orgasmo ou de dor, indagado também sobre a qualidade e o tempo de ereção. Na mulher pergunta-se sobre o retorno da menstruação, se tem lubrificação vaginal frente a excitação sexual, sensação de orgasmo, e informações sobre contraceptivos. Incluem-se ainda dados sobre experiências sexuais anteriores a lesão, doenças venéreas, interesse e freqüência de atividades sexuais, áreas do corpo mais sensíveis, desejo de ter filhos, existência de parceria sexual habitual.

No exame físico avaliamos a sensibilidade superficial, a atividade motora, reflexa ou voluntária a integridade dos órgãos reflexos envolvidos na resposta sexual a finalidade da avaliação é determinar precisamente o nível e extensão da lesão relacionadas aos segmentos sacrais (S2-S3-S4). No homem é preciso avaliar a sensibilidade da pele do pênis, bolsa escrotal e a parte interna das coxas; na mulher, observa-se a sensibilidade do clítores, grandes e pequenos lábios, períneo a parte interna das coxas, importantes avaliar se há resposta a estimulação tátil a à estimulação dolorosa (algodão/agulha) deve-se pesquisar principalmente o tônus do esfíncter anal externo a da resposta do reflexo anal. (Tonicidade do esfíneter e constrição) pode-se potencializar a resposta esfincteriana através do reflexo bulbocavernoso-anal (através da compressão adicional da glande peniana. O indivíduo poderá também ser ou não capaz de comandar voluntariamente a contração do esfíncter anal externo. Resposta motora positiva indica atividade reflexa do centro sacral 
(S2-S-3-S4) a classificação é de lesão tipo neurônio motor superior (N.M.S.) se a resposta for negativa o arco reflexo sacral está lesado, por destruição do centro ou dos nervos sacros. a lesão é então classificada como do tipo neurônio motor inferior (N.M.I.).

A conclusão sobre o nível e extensão da lesão (completa ou incompleta) é dado pela avaliação concomitante da resposta sensitiva e do controle voluntário. Na lesão completa existe ausência de sensibilidade e de controle voluntário do esfíncter anal.

Na lesão incompleta, ocorre ausência de sensibilidade ou falta de controle voluntário.

\section{CLASSIFICAÇÃO DO TIPO DE LESÃO MEDULAR E A FUNÇÃO SEXUAL}

- $\quad$ N.M.S. (Completa) - Presença de contração do esfíncter anal; ausência de sensibilidade e de controle motor voluntário do esfíncter.

- $\quad$ N.M.S. (Incompleta) - Presença de contração do esfíncter anal, presença de sensibilidade tátil ou dolorosa parcial ou controle voluntário do esfíncter.

- N.M.1. (Completa) - Não há tônus, sensibilidade nem controle voluntário do esfíncter anal (ausência do reflexo bulbocavernoso-anal).

- N.M.I. (Incompleta) - Não há tônus nem controle do esfíncter, porém, há sensibilidade.

Obs.: A lesão medular pode destruir um dos ou ambos os centros responsáveis pela ereção e ejaculação ou pode interromper as fibras de comunicações entre eles.

- A lesão medular pode ser completa (transecção) persistindo a atividade reflexa, sem manifestações da influência cortical.

- A lesão medular pode ser incompleta, persistindo atividade reflexas e graus variados de controle cortical.

\section{REFERÊNCIAS ESTATÍSTICAS}

A maioria das investigações estatísticas apresentam conclusões obtidas de questionários e entrevistas com pacientes; e quanto aos avaliados a maioria eram internos ou vivendo em seus lares a pouco tempo, poucos trabalhos envolviam as observações da parceira sexual. 


\section{Única Estatística Brasileira}

\section{A.A.C.D. 1982 - 100 Lesados Medulares do Sexo Masculino}

\begin{tabular}{|c|c|c|}
\hline 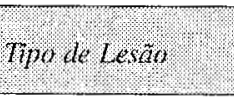 & Enepges & Eiracilagat \\
\hline N.M.S. Completa & $78 \%$ & $15 \%$ \\
\hline N.M.S. Incompleta & $100 \%$ & $15 \%$ \\
\hline N.M.l. Completa & $85 \%$ & $29 \%$ \\
\hline N.M.I. Incompleta & $100 \%$ & $75 \%$ \\
\hline
\end{tabular}

A metodologia utilizada para o cálculo da porcentagem de ereção e ejaculação segue o modelo de Bors e Comarr. Os resultados estão muito acima dos obtidos por outros pesquisadores, o que segundo conclusão da equipe da A.A.C.D. reflete a influência de fatores culturais (o brasileiro confunde potência com masculinidade), levando a dar falsos depoimentos.

\section{Comparação}

A.A.C.D. $1982-100 \mathrm{Lm}-$ Homens

Comarr 1977 - 679 Lm-Homens

\begin{tabular}{|c|c|c|c|}
\hline Tipo de Lesä́n & Fumgan Sextial & commint & A.A.C.D. \\
\hline N.M.S. Completa & $\begin{array}{c}\text { Ereção } \\
\text { Ejaculação }\end{array}$ & $\begin{array}{l}93 \% \\
19 \%\end{array}$ & $\begin{array}{l}78 \% \\
15 \%\end{array}$ \\
\hline N.M.S. Incompleta & $\begin{array}{c}\text { Ercçāo } \\
\text { Ejaculação }\end{array}$ & $\begin{array}{l}98 \% \\
25 \%\end{array}$ & $\begin{array}{r}100 \% \\
25 \%\end{array}$ \\
\hline N.M.I. Completa & $\begin{array}{c}\text { Ereção } \\
\text { Ejaculação }\end{array}$ & $\begin{array}{l}26 \% \\
35 \%\end{array}$ & $\begin{array}{l}85 \% \\
29 \%\end{array}$ \\
\hline N.M.I. Incompleta & $\begin{array}{c}\text { Ereção } \\
\text { Ejaculação }\end{array}$ & $\begin{array}{l}83 \% \\
50 \%\end{array}$ & $\begin{array}{l}100 \% \\
75 \%\end{array}$ \\
\hline
\end{tabular}


Pesquisa Argentina 1970 - I62 L.M. Homem

\begin{tabular}{|c|c|c|c|}
\hline hipo de letrot & thegars: & riacitrugder & 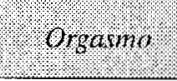 \\
\hline N.M.S. Completa & Reflexa $87 \%$ & Rara - & Ausente \\
\hline N.M.S. Incompleta & $\begin{array}{c}\text { Reflexa e } \\
\text { psicógena } 92 \%\end{array}$ & $\begin{array}{l}\text { Contínua após a creção } \\
\text { reflexa e psicógena } 4 \%\end{array}$ & $\begin{array}{l}\text { Presente com } \\
\text { ejaculação }\end{array}$ \\
\hline N.M.I. Completa & Psicógena $7 \%$ & $\begin{array}{c}\text { Contínua após ereção } \\
\text { psicógena - }\end{array}$ & $\begin{array}{l}\text { Presente com } \\
\text { emissão }\end{array}$ \\
\hline N.M.I. Incompleta & $\begin{array}{l}\text { Psicógena e } \\
\text { reflexa } 86 \%\end{array}$ & $\begin{array}{l}\text { Contínua após ereção } \\
\text { psicógena e reflexa } 10 \%\end{array}$ & $\begin{array}{l}\text { Presente com } \\
\text { ejaculação }\end{array}$ \\
\hline
\end{tabular}

Obs.: As variações são relevantes, mas o que prevalece é a ordem de preservação ou recuperação gradual das funções sexuais. Somando os estudos, apesar das diferenças metodológicas, mais de 1000 casos foram estudados. A ereção está mantida de $63,3 \%$ a $94 \%$, a ejaculação com menor freqüência é conseguida de $3 \%$ a $19,7 \%$, o orgasmo é conseguido de $2,8 \%$ a $14 \%$ e a procriação de $1 \%$ a $\% \%$ dos casos. A função sexual é a mais vulnerável das funções autônomas e é a mais rapidamente afetada, na seguinte sequiência: Orgasmo, Ejaculação, Ereção, Micção e Defecação; sua recuperação é a mais tardia das funções das vísceras pélvicas.

\section{PRÁTICAS USUAIS}

- A ereção usualmente conseguida por estímulo manual sobre a genitália e mantida por constrição da base peniana (efeito torniquete por no máximo 30 minutos).

- A posição escolhida por tetraplégicos é colocar a parceira por cima, paraplégicos podem assumir diversas posturas.

- $\quad$ Cuidados de higiene, lavagem do pênis e esvaziamento da bexiga antes do coito.

- $\quad$ Freqüência de atividade sexual entre aqueles que tiverem experiências sexuais prévias à lesão. 
- Satisfação da parceira usualmente por estimulação oral ou manual, dependendo da aceitação individual.

- Inseminação artificial da companheira como opção para filhos.

- Grande importância da discussão dos aspectos psicológicos do deficiente e da sua parceira durante o aconselhamento sexual.

\section{FERTILIDADE DE PARAPLÉGICOS E TETRAPLÉGICOS}

- $\quad$ Masculina - A capacidade reprodutiva está freqüentemente alterada devido à ausência de ejaculação e as alterações na qualidade do esperma.

- $\quad$ Feminina - A capacidade reprodutiva está conservada, se a gravidez não for desejada, deverão utilizar-se de métodos anti-conceptivos e a gravidez e o parto necessitam acompanhamento médico.

\section{TRATAMENTO DISPONÍVEIS}

lndução da Ejaculação: 1) técnica de injeção intratecal de neostigmina (substância parassimpaticomimética que estimula seletivamente a função sexual/0,3 mg de sulfato de neostigmina aplicações na região lombar provocam no intervalo de uma hora varias ereções a ejaculações); 2) Técnica da administração subcutânea de fisostigmona, utilizada apenas para fins diagnósticos em pacientes com os segmentos TI 2-LI-L2 intactos (injetando no subcutâneo $2 \mathrm{mg}$ de fisiostigmina, após 20 minutos, a masturbação desencadeara a ejaculação); 3) Técnica da eletroestimulação transretal (colocação de um dispositivo no reto composto de um elétrodo para a estimulação da região das vesículas seminais a canais deferentes. O sêmen é ejaculado para a bexiga a depois recolhido para o uso na inseminação artificial.); 4) Técnica da eletrovibração (utilização de um vibrador com frequiência de 70-100 hertz, para estimular a superfície ventral da glande peniana; após período variável de 20 segundos a 4 minutos, surge resposta motora (Movimentos rítmicos do assoalho pélvico, da raiz das coxas e da musculatura abdominal) podendo chegar a ejaculação; a técnica não é indicada para indivíduos com lesão acima de TS por apresentar risco de crise de disreflexia autonômica. 
Tratamento da Impotência: 1) Drogas vasoativas (constituem-se de substâncias químicas que, quando injetadas no pênis, provocam a ereção do pênis, foram experimentadas a fenoxibenzamine, papaverina, papaverina-fentolamina a mais recentemente a prostraglandina e a reginina); 2) Próteses penianas (Técnicas de implante de componentes para substituir a função dos corpos cavernosos, com resultados favoráveis).

\section{ACONSELHAMENTO SEXUAL}

Forma de educação sexual onde a atuação do terapeuta sexual e/ou conselheiros é informativa, porém não diretiva e baseada nos princípios humanistas e nas estratégias gerais da terapia sexual.

\section{Objetivos}

- $\quad$ Educar, informar, conscientizar.

- Sensibilizar e modificar atitudes.

- Diminuir a ansiedade.

- Facilitar a comunicação.

- Flexibilizar o estilo de vida.

- Relativizar os papéis sexuais.

- Modificar comportamentos inadequados.

\section{Princípios}

- $\quad$ Toda pessoa tem direito a expressão sexual plena e responsável.

- $\quad$ O ajustamento sexual é facilitado pela maior comunicação em relação em sexo.

- $\quad$ A integração sexual é um dos aspectos essenciais à saúde plena.

- A expressão sexual é um processo dinâmico, sofre alterações de acordo com as necessidades físicas, as experiências e o meio sóciocultural.

- A aceitação social é secundária a auto-aceitação, inclusive na vertente sexual.

- $\quad$ A sexualidade só pode ser expressa reprimida ou suprimida. 


\section{Programas de Aconselhamento Sexual}

- Grupal ou individual.

- Variam segundo a duração, as etapas, o número de participantes, o critério de seleção dos profissionais e participantes.

\section{Estrutura}

I) Duração: Workshops Intensivos/Cursos Modulares.

II) Etapas: Avaliação/Instrução/Aconselhamento.

III) Participantes: Não existe uma regra rígida, podem os grupos de discussão funcionar bem com seis a doze pessoas incluindo parceiros e profissionais.

IV) Dinâmica: Exposição teórica, Grupos de discussão, Sensibilizações, Dramatizações, etc.

\section{Critérios de Seleção}

Participantes: Homogêneos/Heterogêneos.

Profissionais: Interdisciplinaridade

- Capacidade de estabelecer contatos

- Ter noções de psicologia da relação sexual

- Ter noções de patologias orgânicas

- Imparcialidade

- Conhecimento sobre técnicas de entrevista

- Sentir-se a vontade ao abordar o tema da sexualidade

- Treinamento prévio.

\section{Conteúdo Básico}

- Revisão de anatomia a fisiologia sexual masculina e feminina.

- $\quad$ Repercussões da lesão medular na função sexual.

- Repercussões da esfera afetiva na função sexual.

- $\quad$ Aspectos mais amplos da sexualidade. 


\section{Recursos Didáticos}

- Material audiovisual (diapositivos/filmes/videos).

- Revistas eróticas.

- Textos selecionados.

- Painéis.

- Discussão em grupos.

- Objetos-bonecos, etc.

\section{REFERÊNCIAS BIBLIOGRÁFICAS}

1. Qué es la sexualidad?, de Maria Teresa Gómes Rojas. In: Venciendo Barreras, vol. $6, n^{\circ} 1$, abr./93, pp. 22-25.

2. Impotência? Eso era antes; técnicas para reestabelecer la erección, de Fanny Restrepo Garcia. In: Venciendo Barreras, vol. 7, n 1, abr.-jul./94, pp. 24-25.

3. Facilidades para o amor. In: O Globo, 25/05/94.

4. Forbidden fruit, de Anne Finger. In: New Internationalist, $\mathrm{n}^{\circ}$ 233, jul./92, pp. 8-10.

5. Ajustamento social pleno só com antor e sexo. de Isabel Vieira. In: Integração, ano $2, \mathrm{n}^{\circ} 6$, set./89, p. 10.

6. Prograrna de educação sexual para deficientes mentais, de Regina Ester Gomes Cruz. In: Integração, ano 4, n ${ }^{\circ}$, abr.-jun./92, pp. 17-19.

7. Trabalho em grupo e orientação sexual na clínica de lesão medular, de M. E. P. Casalis \& M. M. M. Spósito. In: Integração, ano 2, n 4, mar./89, pp. 32.35.

8. Paraplégicos tambén e podem ser pais, de Ivadel Batista Alves. In: Integração, ano $2, \mathrm{n}^{\circ} 7$, dez./89, p. 47.

9. Nossos capítulos da sexualidade. In: Jornal do Brasil, 29/06/94.

10. Deficiência não anula a libido, de Edmilson Silva. In: O Globo, 03/07/94.

11. MOONEY, Thomas et alli. Sexual options for paraplegics and quadriplegics. Boston: Little, Brown and Company, 1975.

12. NORDOVIST, Inger. Sexuality and disability - a matter that concerns all of us. Bromma: The Swedish Institute for the Handicapped, 1986.

13. HAMMOND, Margaret et alli (eds.). yes, you can! A guide to self-care for persons with spinal cord injury. Paralyzed Veterans of America, 1989, pp. 217-240.

14. KOCH, Sandra (ed.). The sourcebook of patient education materials for physical medicina and rehabilitation. Houston: D. Armstrong Company, 1988, pp. 556-581. 
15. Correctaid: Erection assistance device -Instructions for - use. Houston: Synergist Limited, 1986.

16. HALE, Glorya (ed.). Manual para minusvalidos: Guia ilustrada para hacer la vida más facil $e$ independiente a los impediso físicos, sus families $1 v$ amigos. Madrid: H. Blame. 1980, pp. 150-161.

17. WALSH, J. J. Understanding paraplegia. Hertford; DOLPHIN, 1974, capítulo 14: Função Sexual na Paraplegia, pp. 93-96.

18. COLE, Theodore et alli. A new programme of sex education and couseling fór spinel! core! injured adults and health care professionals. In: Paraplegia, vol. ii. $\mathrm{n}^{\circ}$ 2. ago./73, pp. 111 1-124.

19. BURKE, David \& MURRAY, D. Duncan. Handbook of spinal cord medicine. London: Macmillan press, 1975, capítulo 10: Função Sexual no Paciente Lesado Medular, pp. 61-65.

20. ROGERS, Michael. Living with paraplegia. London: Faber, capítulo 6, pp. 103-136.

21. CORBET, Barry (ed.). National resource directory: an information guide for persons with spinal cord injury and other physical disabilities. Newton: National Spinal Cord Injury Association, 1985, capítulo IV: Sexualidade, pp. 38-43.

22. PHILLIPS, Lynn et alli. Spinal cord injury: a guide for patient and family. New York: Raven Press. 1987, capítulo 12: Sexo e Intimidade, de autoria de Mark Ozer \& Lynn Phillips, pp. 147-160.

23. GAUDERER, E. C. Autismo. CORDS, capítulo 9: Sexo e Sexualidade e o Profissional de Educação e Saúde, pp. 260-280.

24. LIPPI, Novais Marilda. Sexo para deficientes mentais, sexo e o excepcional dependente e não dependente. Cortez Editora, SP, 1981.

25. DOCHERTY, James. Growing up, um guia para crianças e seus pais. Editora Científica Nacional, RJ, 1986.

26. GLAT. Rosana. Somos iguais a você. Agir Editora, RJ, 1989.

27. LOUREIRO MAIOR, I. M. M. Reabilitação sexual do paraplégico a tetraplégico. Editora Revinter, RJ, 1988.

28. MARCONDES, Ricardo, No silencio do sexo. Editora Record. RJ, 1994.

29. ASSUMPÇÃO, F. B. e SPROVIER, M. H. S. Sexualidade e deficiência mental. Ed. Moraes, SP, 1987. 